\title{
Modelling of Compound Parabolic Concentrators for Photovoltaic Applications
}

\author{
A. Antonini ${ }^{1, *}$, M. Ste fancich ${ }^{2}$, J. Coventry ${ }^{3}$, A. Parretta ${ }^{4,5}$ \\ ${ }^{1}$ Italian Institute of Technology, Via Morego 30, 16163 Genova (GE), Italy \\ ${ }^{2} \mathrm{M}$ asdar Institute of Technology, Abu Dhabi, United Arab Emirates \\ ${ }^{3}$ Wizard Power Pty Ltd, 11 McKay Gardens, Turner ACT 2612, Australia \\ ${ }^{4}$ Physics Department, University of Ferrara, Via Saragat 1, 44122 Ferrara (FE), Italy \\ ${ }^{5}$ ENEA C.R. "E. Clementel”, Via Martiri di Monte Sole 4, 40129 Bologna (BO), Italy
}

\begin{abstract}
In this paper ways of using compound parabolic concentrators as primary optical elements for concentrated photovoltaics are evaluated. The problems related to these classical non-imaging optical elements for photovoltaics applications have been evaluated by modelling different types of linear and point focus concentrators. Particular consideration is given to the issues of manufacturability and cost. The non-uniformity of the flu x resulting at the concentrator exit aperture has been considered and some solutions are proposed in order to reduce adverse effects on performance, as well as to increase the angular tolerance of the system.
\end{abstract}

Keywords Solar Concentrators, Photovoltaic Conversion, Optical Design

\section{Introduction}

Concentrator photovoltaics (CPV) systems[1,2] in use today can be divided, in first instance, into two main categories: Fresnel lens refractors and parabolic reflectors. Both can be either point focus (3D) or linear focus (2D) concentrators. The concept of the compound parabolic concentrator $(\mathrm{CPC})$ as a primary concentrator has received some attention in the field of build ing integrated $\mathrm{PV}$, but only for low concentration $(<5 \mathrm{x})$ non-tracking applications [1-3] with few exceptions [4,5]. For solar tracking applications, CPCs offer the possibility of high solar concentration ratios, in principle approaching the theoretical limits[6,7]. However, one of the largest hurdles in the use of CPCs for primary optics in PV concentrators is their unwieldy character and the necessary high material usage. This can in part be offset by reducing the length of the CPCs with the so called truncated CPCs, or T-CPCs, which use far less material with only a minor reduction in concentration ratio and optical efficiency[6,8]. Despite this improvement, the surface area of the primary optical component remains high compared to a lens or a parabolic mirror. In this paper, some new possibilities for cheap and easily manufactured CPCs will be discussed, as alternative of the more diffused concentrators based on lenses or

* Corresponding author:

andrea.antonini@iit.it (A. Antonini)

Published online at http://journal.sapub.org/optics

Copyright (C) 2013 Scientific \& Academic Publishing. All Rights Reserved parabolic troughs for the medium and medium-high levels of concentration positioned on trackers for large scale, field applications.

CPCs offer some technical advantages: compared to a classic parabolic reflector, a CPC can be used with a less precise tracking system, due to the flat optical efficiency response, opening up the possibility of using cheaper commercial trackers not normally suitable for CPV; moreover, compared to a Fresnel lens, the optical efficiency of a CPC is higher. The best designed lenses currently available show optical efficiencies $<90 \%[9,10]$, while the performances of CPCs can be limited with good approximation only by the reflectivity of the optical surface; indeed, the smoothness of the CPC's surface helps to strongly reduce the manufacturing defects limiting more complex, structured designs. Therefore, optical efficiency can be higher than $90 \%$ with advanced reflective films or coatings, such as those discussed in this paper. Additionally, some of these materials permits to filtering unwanted portions of the solar spectrum, which is advantageous in minimizing cooling requirements for the solar cell.

In common with most high concentration PV systems, the use of a flux homogenizer could be considered. As discussed in this paper, the flux profile at the outlet aperture of a CPC is highly non-uniform, and therefore the impact on cell performance for a concentrator cell can be deleterious. The design of the homogenizer suited to a CPC is discussed.

\section{Background}


Descriptions of the CPC began appearing in literature in the mid-1960s[11,12]. As described by[6], the CPC was used for many different applications, ranging from high-energy physics to solar energy collection. In the field of solar energy, CPCs have mainly been used in solar thermal applications, most commonly as static linear collectors focusing light onto evacuated tubes at low concentration $(\sim 1.5 \mathrm{x})$. There are applications where CPCs are used as the primary concentrator with photovoltaic cells, and other where they have been considered as secondary, non-imaging concentrator stage for some PV concentrator systems. Some projects have looked at the use of CPC troughs for combined PV-thermal (PV/T) applications [13]. In Sweden, Brogren firstly explored the use of CPCs for $\mathrm{PV} / \mathrm{T}$ applications that require water for space heating[14], then further investigated $[15,16]$.

One of the advantages that CPCs offer with respect to conventional imaging systems (parabolic mirrors and some Fresnel lenses) is their higher tolerance to misalignments with respect to the sun disk direction. Since CPCs approach the behaviour of ideal concentrators, their optical efficiency can be kept closed to unity up to the acceptance angle with a reduction factor for the entrance flux of only the cosine of the misalignment angle. As a consequence, for a given optical concentration ratio, they show the largest acceptance angle. The requirement on tracking accuracy is therefore lower, compared to other concentrators with the same concentration ratio.

Most Fresnel lens systems concentrate light onto single solar cells with a point focus approach, rather than onto dense arrays of series connected cells. The significant advantage of this approach is that the problems of cell current mis match are largely avoided (cells will still need to be series connected with other cells to build voltage, but, if the optical efficiency of each lens is the same, then cell currents should also be well matched). Single cells are able to tolerate a reasonably high degree of light non-uniformity, however, as discussed by $[17,18]$, there can be a reduction in efficiency. In addition, when lenses for high concentration are used in conjunction with multi-junction cells, the effect of the non-uniformity can be a more serious problem because of the different light deflections for the different wavelengths converted by the cells in stack[19]. This problem is avoided for concentrators using reflective optics. Secondary flu $x$ ho mogenisers can be emp loyed to give near uniform light distribution on the cells. They are frequently used for both lens systems[19,20] and parabolic dishes [21-23]. The simplest flux homogenisers are rectangular boxes with reflective sidewalls (i.e. a kaleidoscope). Solid blocks made of plastic or glass, using the principles of total internal reflection, may realize the same design. However, care must be taken to avoid melting due to strongly focused spots of concentrated light.

\section{CPC Design}

The CPCs can be designed to concentrate light in either two or three dimensions. Obviously, the 2D-CPC has a lower concentration factor. According to[6], they can be designed following the Eq.s $(1,2)$, as a function of the concentration ratio $C(N D)$, the required acceptance angle $\theta i$ and the refractive index nout of the material at the exit aperture, for a $\mathrm{CPC}$ with ND dimensions:

$$
\begin{gathered}
L=\frac{\left(a_{\text {in }}+a_{\text {out }}\right)}{\operatorname{tg} \theta_{i}} \\
C^{(N D)}=\left[\frac{n_{\text {out }} \sin \theta_{\text {out }}}{n_{i} \sin \theta_{i}}\right]^{N D-1}
\end{gathered}
$$

where $\mathrm{L}$ represents the length of the concentrator, ni is the refractive index of the medium at the entry, (usually air, i.e. with $n i=1$ ), a in and aout are the entrance and exit apertures radii respectively, as illustrated in the standard representation of Fig. 1. In order to utilize the advantage given by the re fractive index at the outlet nout, it is important to have the solar cell in optical contact with a transparent, dielectric material with $\mathrm{n}>1$ as, for example, silicone; the interface should be matched to minimize the reflection losses at the receiver front surface.

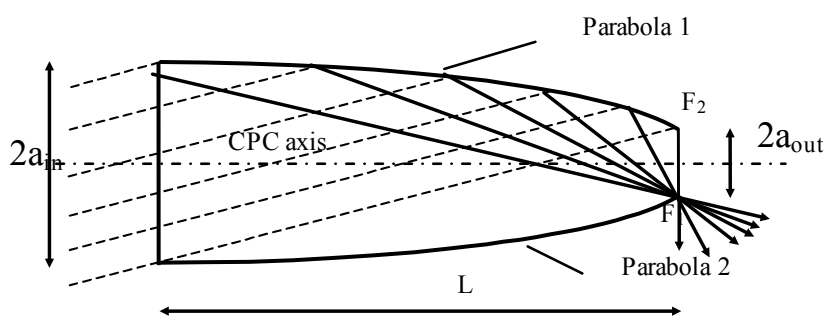

Figure 1. Geometrical construction of a CPC; the dashed lines represent raystilted of the acceptance angle of the structure

For PV, and in general for all the energy production applications, it is important to reduce the cost of the system to a minimum; therefore, it is reasonable to consider CPCs filled with air rather than with materials capable to ensure higher concentration factors (with refractive indexes greater than one). Even with this assumption, the highest theoretical limits for optical concentration in air is fairly high: $216 \mathrm{x}$ for $2 \mathrm{D}$ concentrators, and $\sim 46,000 \mathrm{x}$ for $3 \mathrm{D}$ concentrators [6].

\section{2D Concentrator Systems}

2D-PV concentrator systems have been extensively studied, both theoretically and experimentally, with both reflecting mirrors[24,25] as well as with lenses[26,27]. The 2D-CPCs are not commonly used in PV applications because the length of the two parabolic reflective walls appears to be excessive for large scale purposes. For example, for a concentration factor of $30 \mathrm{x}$ on a $4-\mathrm{cm}$ wide cell (the same size used in the EUCLIDES project[24]), the length of an ideal CPC collector results $19 \mathrm{~m}$ long. Even an halved-CPC is too long for any practical applications. The $2 \mathrm{D}-\mathrm{CPC}$ is an ideal concentrator in terms of light concentration factor for a given acceptance angle, but, for PV applications, the ideal characteristics for the optical 
efficiency are not strictly required. The necessity for the optical systems, in fact, is to operate at an incident angle range for the impinging radiation at which its efficiency is the highest. In general, for the CPCs, the enhancing of the concentration factor leads to an increasing of the object length; besides, the higher the concentration ratio, the lower the angular acceptance of the system. The shortening of the CPC involves a mall loss of concentration and a small gain of angular tolerance, if the truncation is produced in the region of the parabola where the sloping is lower, i.e. from the entrance aperture. So, it is possible to design a truncated $\mathrm{CPC}$ concentrator far shorter than the ideal one for a given concentration factor, reducing the length of an ideal CPC of higher concentration ratio and of lower angular acceptance, achieving a structure with higher angular acceptance respect to the ideal one and considerably shorter.

Eq. (3) defines a T-CPC, with the main parameters given in Fig 2, as exhaustively described in[2].

$$
L_{T}=a_{T} \frac{\left(1+\sin \theta_{\mathrm{i}}\right) \cos \left(\phi_{T}-\theta_{i}\right)}{\sin \left(\phi_{T}-\theta_{i}\right)\left(1+\sin \theta_{\mathrm{i}}\right)-\sin ^{2}\left(\phi_{T} / 2\right)}
$$

To avoid the problem of excessively large lenses and long focal distance, PV lens concentrators typically consist of a number of small modules rather than a single large lens. CPCs designs could also be suitable to such a configuration. If very narrow solar cells were used for a $2 \mathrm{D} \mathrm{CPC}$, the length of the collector would be suitable for industrial fabrication technologies, and for tracking systems similar to those currently used for lens arrays. Suitable cells for th is purpose are, for e xample, the concentrator Sliver ${ }^{\mathrm{TM}}$ cells developed at the Australian National University. Sliver cells have a width of about $1 \mathrm{~mm}$, and could work efficiently under a concentration factor of about $30 \times[28,29]$.

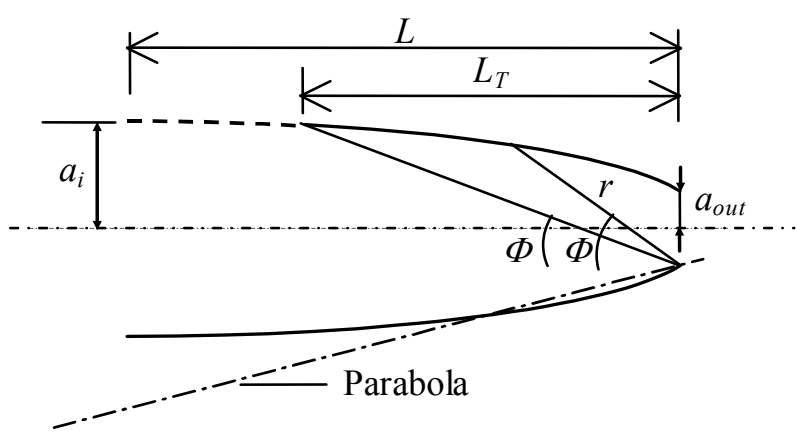

Figure 2. Schematic representation of a truncated CPC; the complete CPC of length $\mathrm{L}$ is shortened up to the length equal LT

Encapsulating the solar cell with silicone can give an optical improvement by increasing the refractive index of the object. Eq. (2) shows that an increase in the refractive index $n_{\text {out }}$ increases the optical performances of the concentrator. By partially filling the evacuated solid, the object can accept rays otherwise rejected, due to the refraction of light at the air-silicone interface. This effect is shown in the ray traces in Fig. 3. The figure shows the ray trace close to the exit aperture of a truncated 2D-CPC, $15-\mathrm{cm}$ long, with an exit total aperture $2 \times a_{\text {out }}=1 \mathrm{~mm}$ and a concentration factor of $30 \times$, for a ray beam misaligned at $0.6^{\circ}$ and with the solar angular divergence of $0.26^{\circ}$. Fig. 3a shows the outlet of the concentrator without the dielectric, while Fig. $3 b$ shows the ray trace of the same rays when the concentrator is filled with a material with refractive index $n=1.49$ (i.e. PMMA for $\lambda=$ $600 \mathrm{~nm}$ ) for a length of $25 \mathrm{~mm}$ starting from the exit. The latter configuration is able to tolerate misalignment up to $0.6^{\circ}$. The structure behaves as a simplified form of a two-stage CPC[3], while the surface curvature of the object is like that of a single CPC.

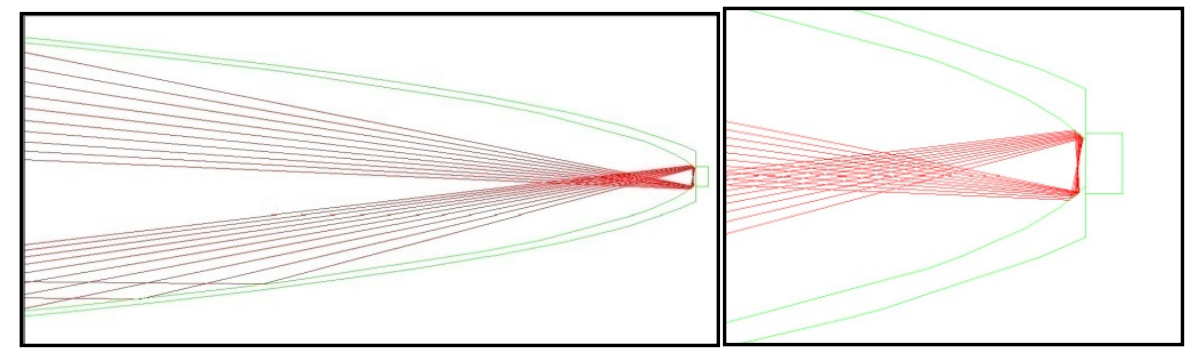

Figure 3a. Raytrace on a $2 \mathrm{D}$, truncated $\mathrm{CPC}$ for a beam of incident rays tilted of $0.6^{\circ}$ respect to the $\mathrm{CPC}$ axis; the struct ure is not filled with dielectric material. The incoming beam is the bottom one

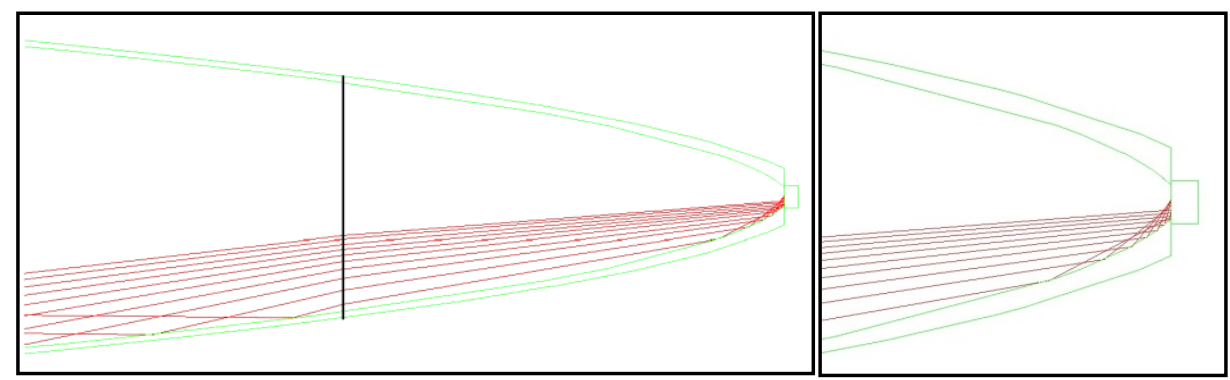

Figure 3b. The same raytrace on a CPC partially filled at the exit for $2.5 \mathrm{~cm}$ with dielectric with $\mathrm{n}=1.49$ 


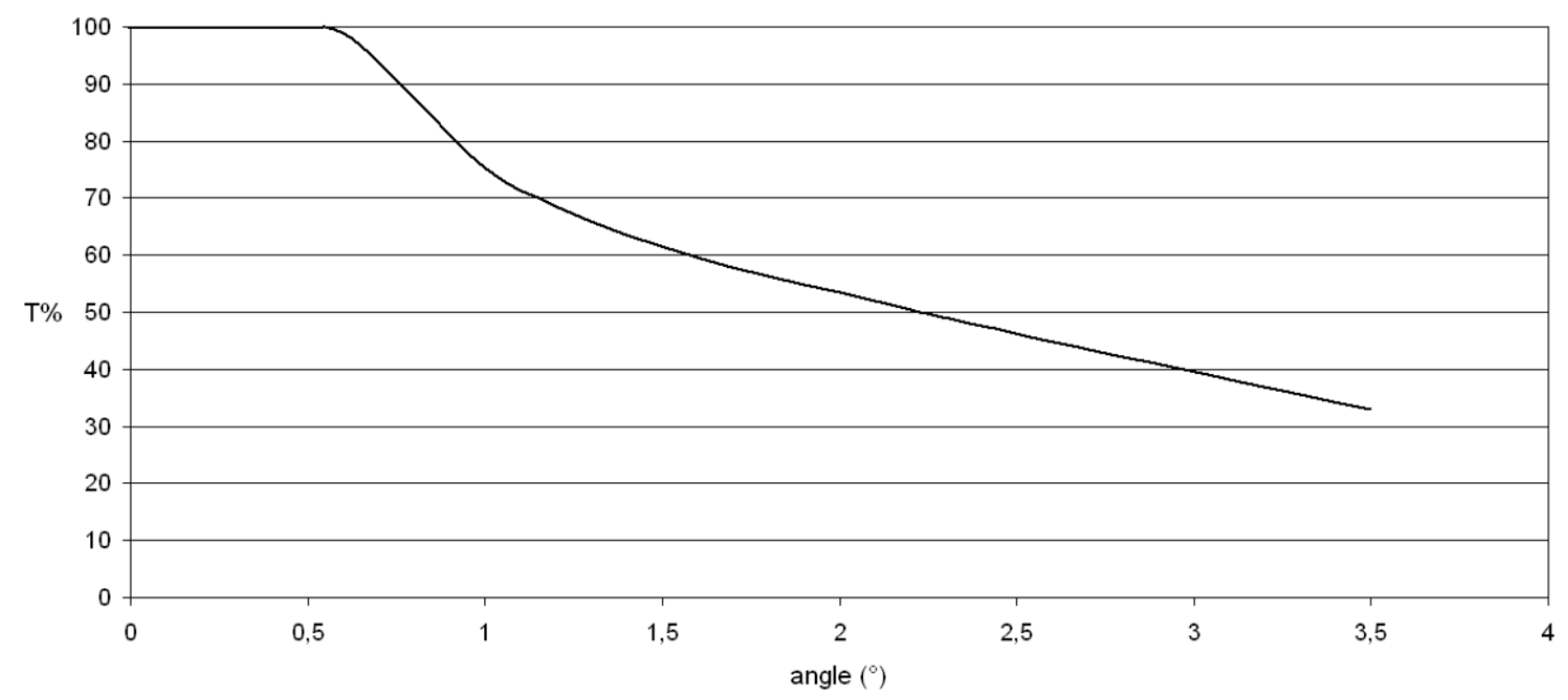

Figure 4. Transmission-angle characterist ic of the partially filled 2DT-CPC

The partially filled, truncated $\mathrm{CPC}$ can be analysed as a two stage CPC, where the first stage is a $T$-CPC with a low exit angle $\theta_{\text {out }}$ and with an exit material with $n>1\left(\theta_{\text {out }} \cong 15^{\circ}\right.$ and $n=1.49$ in the example of Fig. $3 b$ ), and the second stage is another $T$-CPC with an exit angle $\theta_{\text {out } 2}$; this last exit angle can be selected a little lower than $90^{\circ}$, in order to achieve the higher level of concentration for the selected angular acceptance. Because of the rays outgoing with the higher exit angle are the rays incoming with the higher angle of incidence respect to the optical axis of the system, the $\theta_{\text {out }}$ corresponds at the inlet angular acceptance for the second stage. The acceptance angle is here defined as the highest entrance angle for which all the light is transferred to the exit aperture.

As the truncation of the considered objects reduces their lengths, the incident, acceptance angle $\theta_{i}$ has a smaller value for a given concentration factor $C$ than the case of two ideal, longer CPCs, series connected. The incidence acceptance angle $\theta_{i, \text { ideal }}$ for two complete CPCs series connected is derived from the relationship given in Eq. (4), with an assumed total concentration factor $C$. Consequently, the transmission-angle curve hasn't a cut off angle for incident beams in correspondence of the acceptance value as for ideal concentrators, but it has a slope for $\theta>\theta_{i}$, as shown, for the considered case, in Fig. 4.

$$
\begin{aligned}
& C_{\text {ideal }}^{(N D)}=C_{1, \text { ideal }} \times C_{2, \text { ideal }} \\
& =\left[\frac{n_{\text {out }} \sin \theta_{\text {out }}}{n_{i} \sin \theta_{i, \text { ideal }}}\right]^{N D-1}
\end{aligned}
$$

This kind of concentrator, because of its particular form, requires protective glass at the inlet aperture, to avoid the detrimental effect of dirty deposition on the large concave area. This element could be positioned on the complete structure, with an antire flection coating on it, usually acting as self-cleaning surface as well, to reduce the optical losses for the Fresnel reflection at its interfaces. Considering the different cases of presence of uncoated dielectric surfaces, the optical efficiencies obtained by simulation with the software TracePro ${ }^{\circledR}$ of a CPC $15-\mathrm{cm}$ long, with an exit aperture of $1 \mathrm{~mm}$ and a concentration factor of $30 \times$, for diffe rent misalignment values are summarized in Tab. 1; the material properties considered for the reflector are a specular reflectance of $94.87 \%$, absorbance of $5 \%$ and $0.13 \%$ of integrated BRDF. The BRDF is the Bidirectional Reflectance Distribution Function defined as the scattered radiance per unit incident irradiance; mathematically it's expressed as in Eq. (5).

$$
\operatorname{BRDF}\left(\theta_{\mathrm{i}}, \varphi_{\mathrm{i}}, \theta_{\mathrm{s}}, \varphi_{\mathrm{s}}\right)=\frac{d L_{s}\left(\theta_{\mathrm{s}}, \varphi_{\mathrm{s}}\right)}{d E_{i}\left(\theta_{\mathrm{i}}, \varphi_{\mathrm{i}}\right)}
$$

Where $\theta_{\mathrm{i}}, \phi_{\mathrm{i}}$ represent the angles of incidence for the incoming radiation, in spherical coordinates, while $\theta_{\mathrm{s}}, \phi_{\mathrm{s}}$ are the angles indicating the scattering direction. $L_{s}$ is the scattered radiance, while $E_{i}$ is the incident irradiance. This optical property has been introduced to consider the slight effect of the light diffusion at the reflector surfaces. Because of the Fresnel reflection at the interfaces of materials of different refraction indexes, portion of the incident light flux is back reflected at the interfaces of the protective glass and of the encapsulant; this factor of losses, common with every concentrator system using lenses, can be strongly reduced depositing an antireflection layer on the surfaces, which are, in this case, all planar.

The very thin and long illuminated area of this proposed design has the additional advantage of a very high perimeter/surface ratio for the $\mathrm{PV}$ device, which permits to cool down the cells using passively, maximizing the thermal spreading effect at the receiver level.

The necessity of flux uniformity on a single cell significantly depends on the particular kind of cell employed; 
indeed, the cell size, the contact pattern and coverage, the doping levels and the external circu it configurations play all an important role. In the supposed case of Sliver cell used for the 2D-CPCs system, there's a fairly high tolerance for non-uniformity on the device, because the emitter contact is placed on the side of the device, and its small dimension is in the direction perpendicular to the incoming radiation, which is of the order of the electrons diffusion length, for $\mathrm{Si}$ with lifetime higher than $200 \mu \mathrm{s}$. For symmetrical reasons, the uniformity along the long dimension of the device is ensured, so uniform light could be expected along the string of series connected cells. A flux profile along the short side of the cell is graphed in Fig. 5 for different misalignments, with an encapsulating material with the optical properties of PMMA filling the CPC up to $25 \mathrm{~mm}$ from the cell plane.

a)
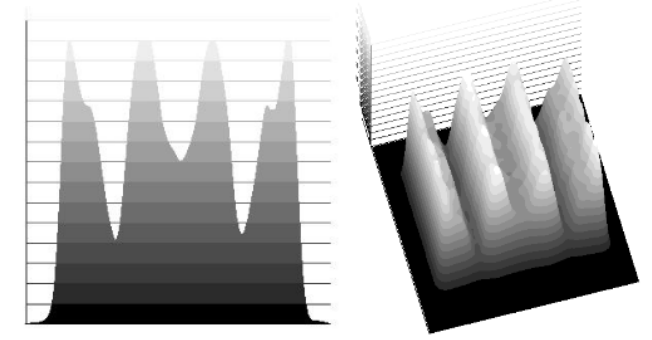

b)
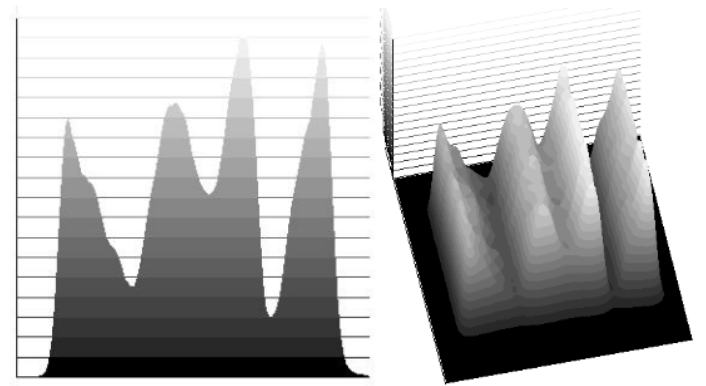

c)
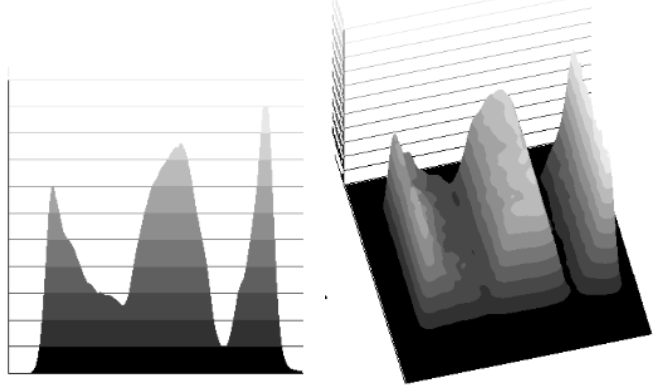

d)
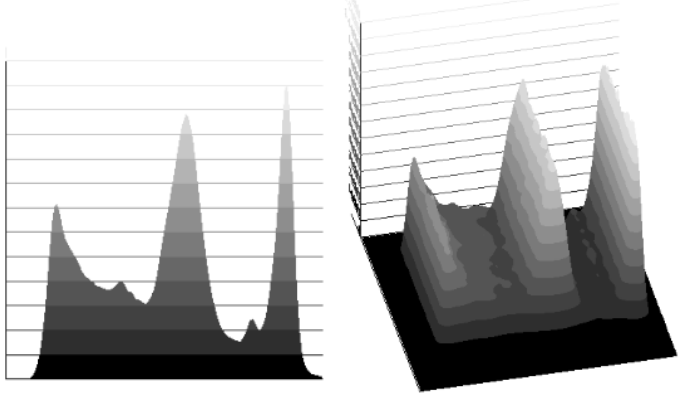

Figure 5. Lat eral (left) and $3 \mathrm{D}$ view (right) of the energy flux distribution on a sector of the receiver for the $2 \mathrm{D}, 30 \times \mathrm{CPC}$ considered, from optical simulations, for four different angle of misalignment (including the solar divergence effect): a) $0^{\circ}$; b) $0.2^{\circ}$; c) $0.4^{\circ}$; d) $0.6^{\circ}$
Table 1. Optical efficiency of a reflective, 2D-CPC of $30 \times$ concentration factor, for different misalignment angles and for different characterist ics of fabrication: (a) no protective glass and no encapsulant; (b) no protective glass, $25 \mathrm{~mm}$ of encapsulant, without ARC; (c) $5 \mathrm{~mm}$ of protective glass and $25 \mathrm{~mm}$ of encapsulant, without ARC; (d) $5 \mathrm{~mm}$ of protective glass, $25 \mathrm{~mm}$ of encapsulant and single MgF2 ARC layer on each interface. The specular reflectance of the surfaces adopted is $94.87 \%$, while glass and encapsulant have been modelled with refraction index $n=1.49$

\begin{tabular}{|c|c|c|c|c|}
\hline Angle $\left(^{\circ}\right)$ & (a) & (b) & (c) & (d) \\
\hline $0^{\circ}$ & $94.5 \%$ & $88.4 \%$ & $81.6 \%$ & $88.5 \%$ \\
\hline $0.2^{\circ}$ & $94.36 \%$ & $88.4 \%$ & $81.6 \%$ & $88.5 \%$ \\
\hline $0.4^{\circ}$ & $82.9 \%$ & $88.6 \%$ & $81.8 \%$ & $88.6 \%$ \\
\hline $0.6^{\circ}$ & $57.1 \%$ & $87.6 \%$ & $81.0 \%$ & $87.8 \%$ \\
\hline
\end{tabular}

\section{3D Concentrator Systems}

In the case of 3D-CPCs it's possible to consider a system assembly similar to that used with a 3D-lenses concentrator. An illustration of an array of these 3D-CPCs objects is shown in Fig. 6.

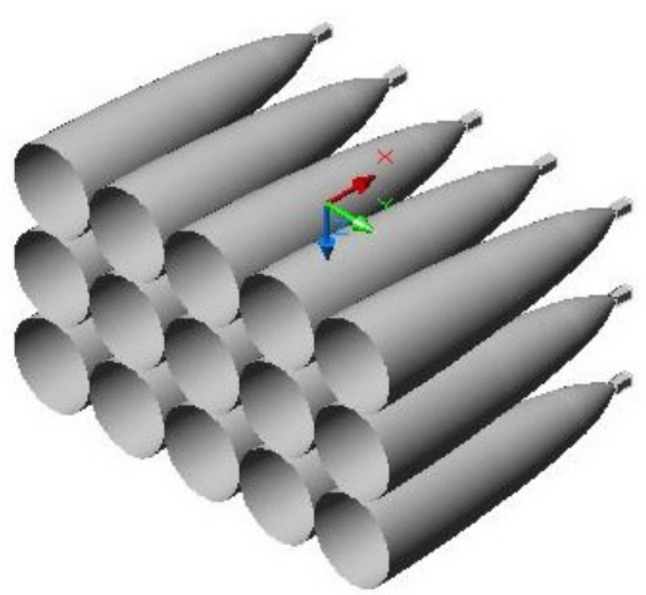

Figure 6. $3 \mathrm{D}$ view of an array of $3 \mathrm{D}-\mathrm{CPC}$, each one with a terminal kaleidoscope for the light flux homogenisation

One important characteristics for PV applications of these $3 \mathrm{D}$ concentrators is the very high non-homogeneity in the spatial flux distribution produced at the exit aperture, as shown, for example, in Fig. 7, for a truncated CPC with a concentration ratio of $115 \mathrm{x}$ and a length of $30 \mathrm{~cm}$, with an incident radiation directed along the optical axis of the concentrator, with the solar angular distribution of $0.26^{\circ}$.

A method to correct this effect is to employ a light mixer to redis tribute the light on the exit area. To achieve this result it is necessary to break the symmetry of the system as described in[19,32]. The strong non-linearity introduced by these changes of geometry produces a chaotic behaviour in the determin istic path of the rays. A well known method is the use of a kaleidoscope with squared section and reflective walls at the CPC outlet. Depending on the mixer unit length it is possible to achieve different levels of uniformity for the illu mination flux on the target area. For practical purposes it is important to find a trade-off between the length of the 
kale idos cope and the level of flux uniformity; indeed, using a non-ideal reflector, the optical losses introduced by each reflection on the mixer walls significantly reduce the concentrator optical efficiency. Moreover, if the kaleidoscope and a portion of the CPC is filled with a dielectric, as previously described for $2 \mathrm{D}-\mathrm{CPCs}$ in order to increase the angular acceptance of the concentrator, a material with a very low absorption coefficient has to be selected. Considering a reflector with a $94.87 \%$ of specular reflectance, $5 \%$ absorbance and $0.13 \%$ of integrated BRDF as before, and a dielectric with the PMMA optical properties which completely fills the 3-cm long kaleidoscope and fills the $\mathrm{CPC}$ outlet for $1.4 \mathrm{~cm}$, the simulated performances are reported in Tab. 2, for different incident angles of a beam with the solar divergence. From the results in the Tab. 2, the energy loss due to multiple reflections at the kaleidoscope walls is evident. Indeed, the fraction of incoming rays achieving the exit aperture is close to 1 (column 4), but a significant part of the radiation energy is absorbed, even for a fairly good reflector with the characteristics specified before. The variation in the flux uniformity as function of the mixer length for normal incidence of the solar radiation for the truncated CPC unit is considered without dielectric filling, and is reported in Fig. 8.
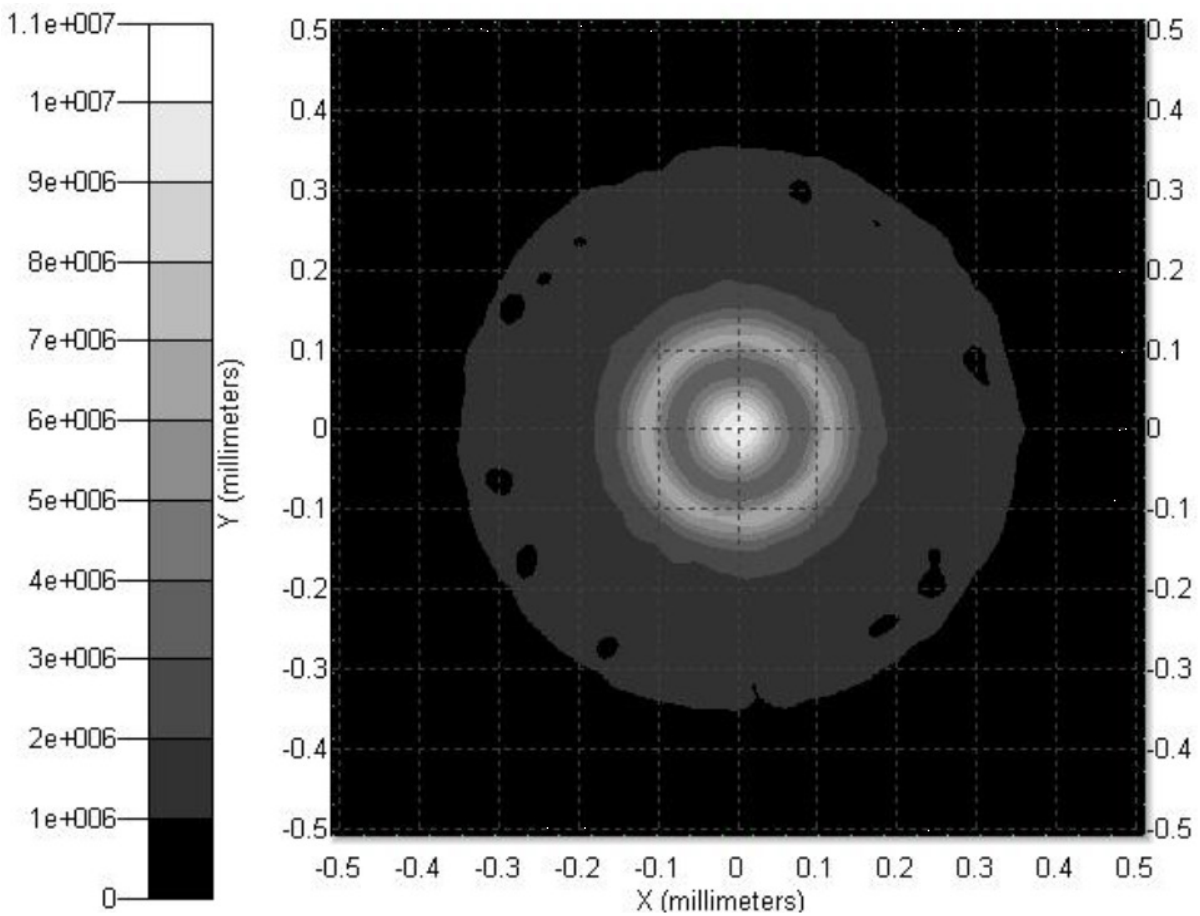

a)

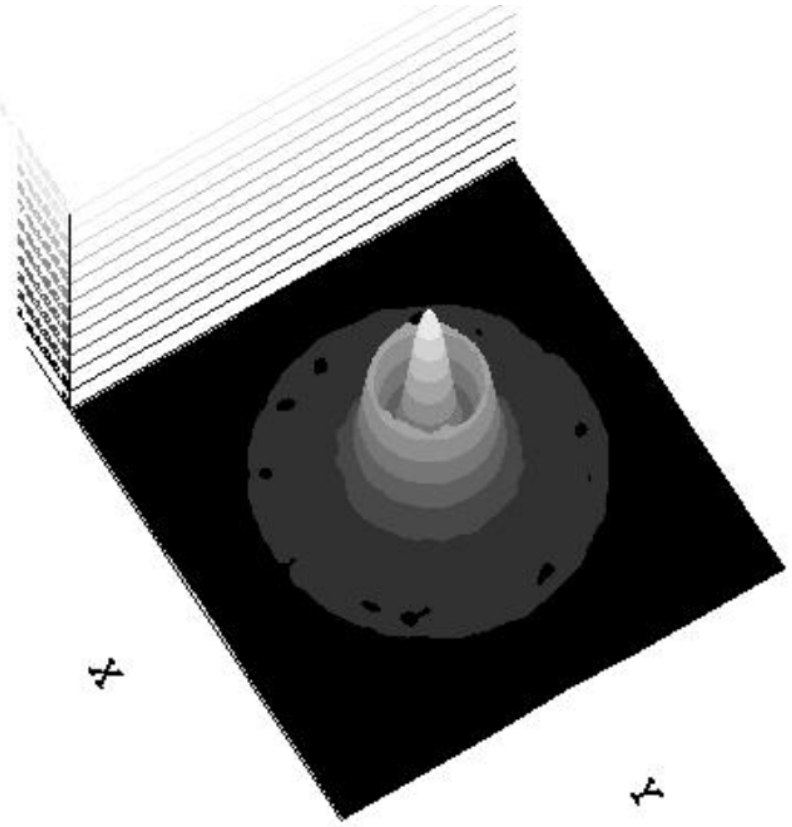

b) 


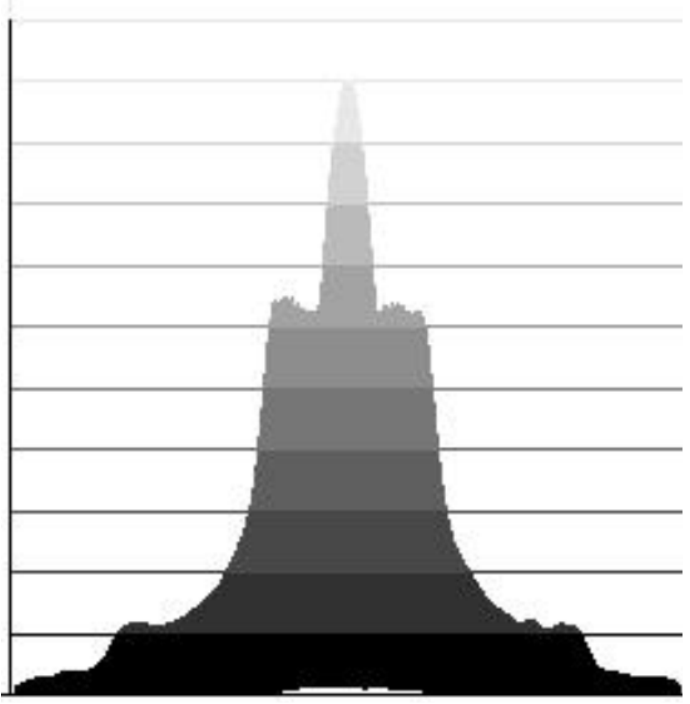

c)

Figure 7. Top (a), 3D (b) and lateralview (c) of the energy light flux distribution at the exit aperture of the $115 \times 3 \mathrm{D} \mathrm{CPC}$; the intensity scale is in arbitrary units

Table 2. Optical efficiency and fraction of collected rays for the $115 \times, 3 \mathrm{D}-\mathrm{CPC}$ with a 3 -cm long kaleidoscope at the exit aperture, for different misalignment angles; the results are considered without and with the part ial filling of the output of the structure with a transparent dielectric with $n=1,49$. The specular reflectance of the surfaces adopted in the model is $94.87 \%$

\begin{tabular}{|c|c|c|c|}
\hline Misalignment angle $\left(^{\circ}\right)$ & $\begin{array}{c}\text { Optical efficiency (Without } \\
\text { partial filling of dielectrics) }\end{array}$ & $\begin{array}{c}\text { Optical efficiency (With partial } \\
\text { filling of dielectrics) }\end{array}$ & $\begin{array}{c}\% \text { of collected rays (With } \\
\text { part ial filling of dielectrics) }\end{array}$ \\
\hline $0^{\circ}$ & $78.3 \%$ & $72.0 \%$ & $99.95 \%$ \\
\hline $0.5^{\circ}$ & $78.4 \%$ & $72.2 \%$ & $99.95 \%$ \\
\hline $1^{\circ}$ & $78.6 \%$ & $72.5 \%$ & $99.95 \%$ \\
\hline $1.5^{\circ}$ & $77.6 \%$ & $72.9 \%$ & $99.95 \%$ \\
\hline $2^{\circ}$ & $74.9 \%$ & $71.5 \%$ & $99.91 \%$ \\
\hline $25^{\circ}$ & $67.2 \%$ & $69.0 \%$ & $99.28 \%$ \\
\hline $3^{\circ}$ & $41.4 \%$ & $65.1 \%$ & $94.75 \%$ \\
\hline
\end{tabular}
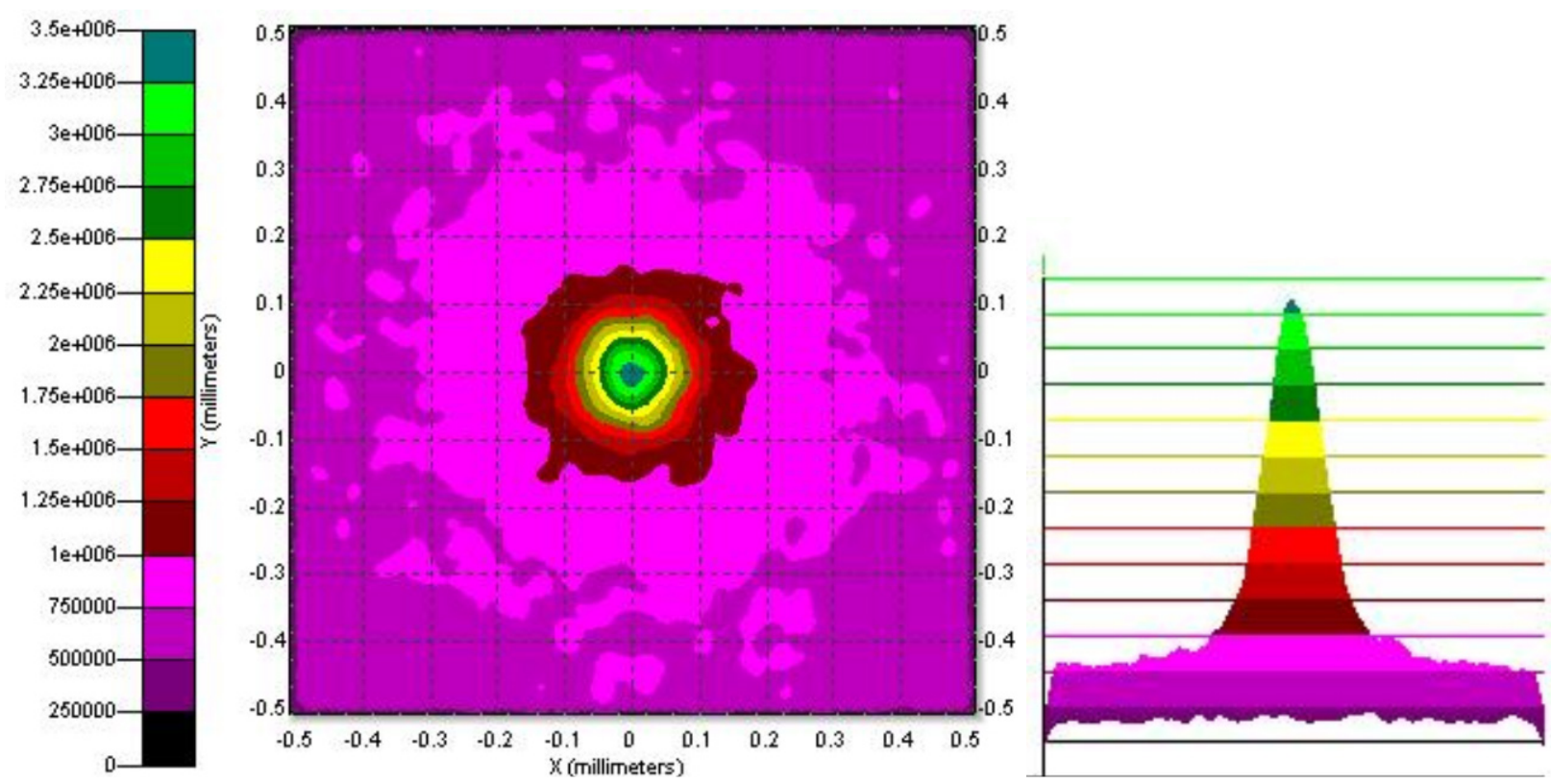

(a) 


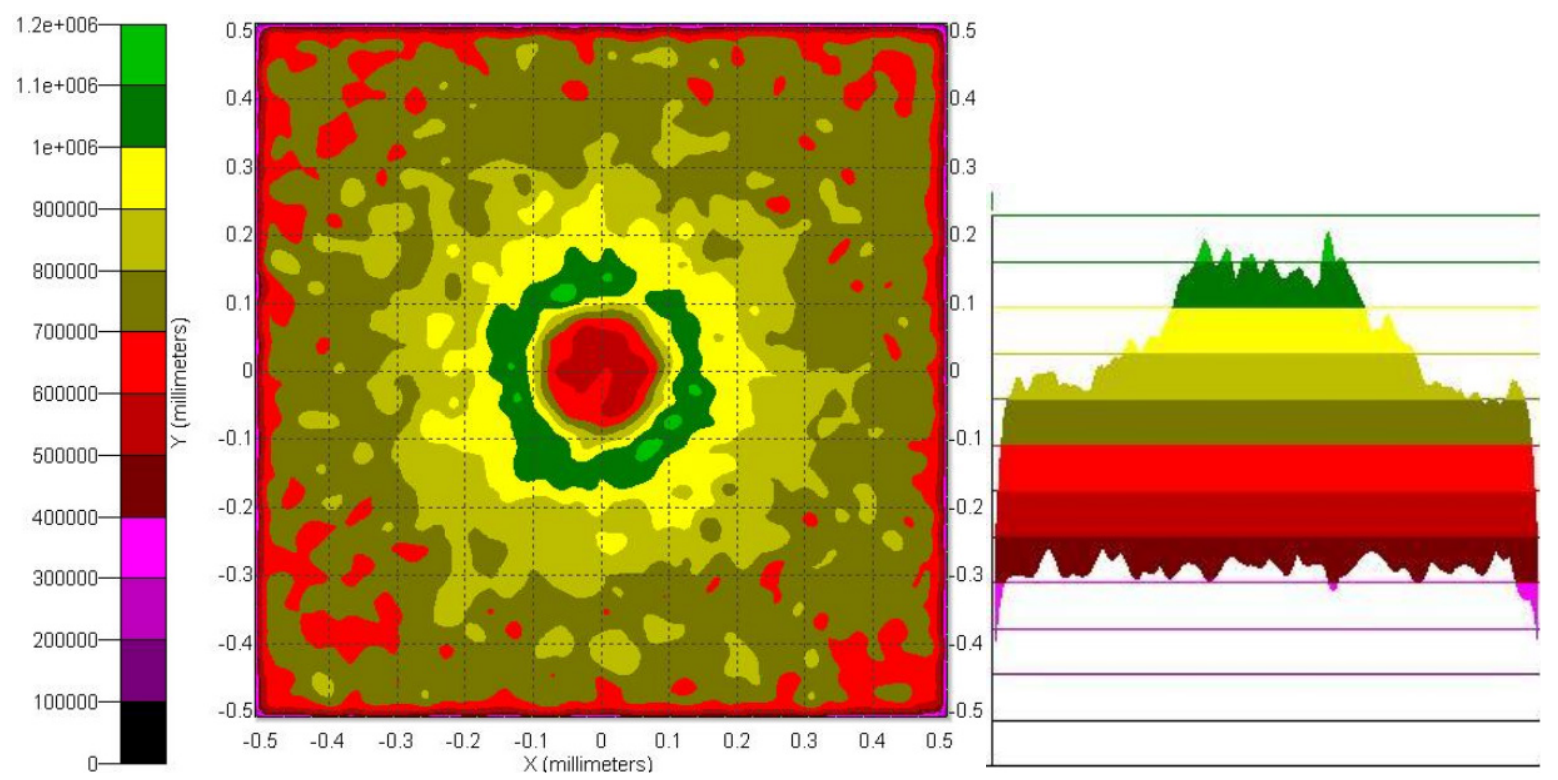

(b)

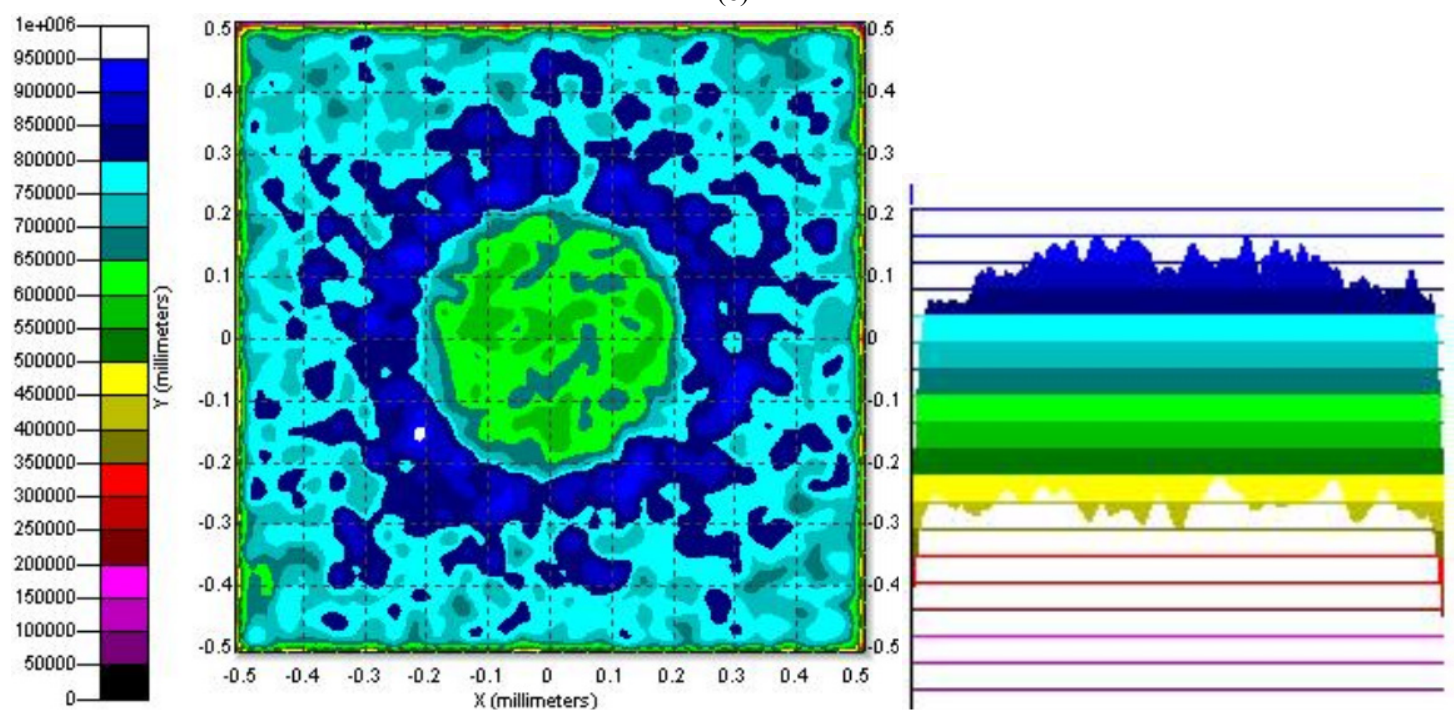

(c)

Figure 8. Flux distribution on the target (map on the left and lateral profile on the right), without dielectric, for different mixer lengths: (a) $2 \mathrm{~cm}$, (b) 2.5 $\mathrm{cm}$, (c) $3 \mathrm{~cm}$
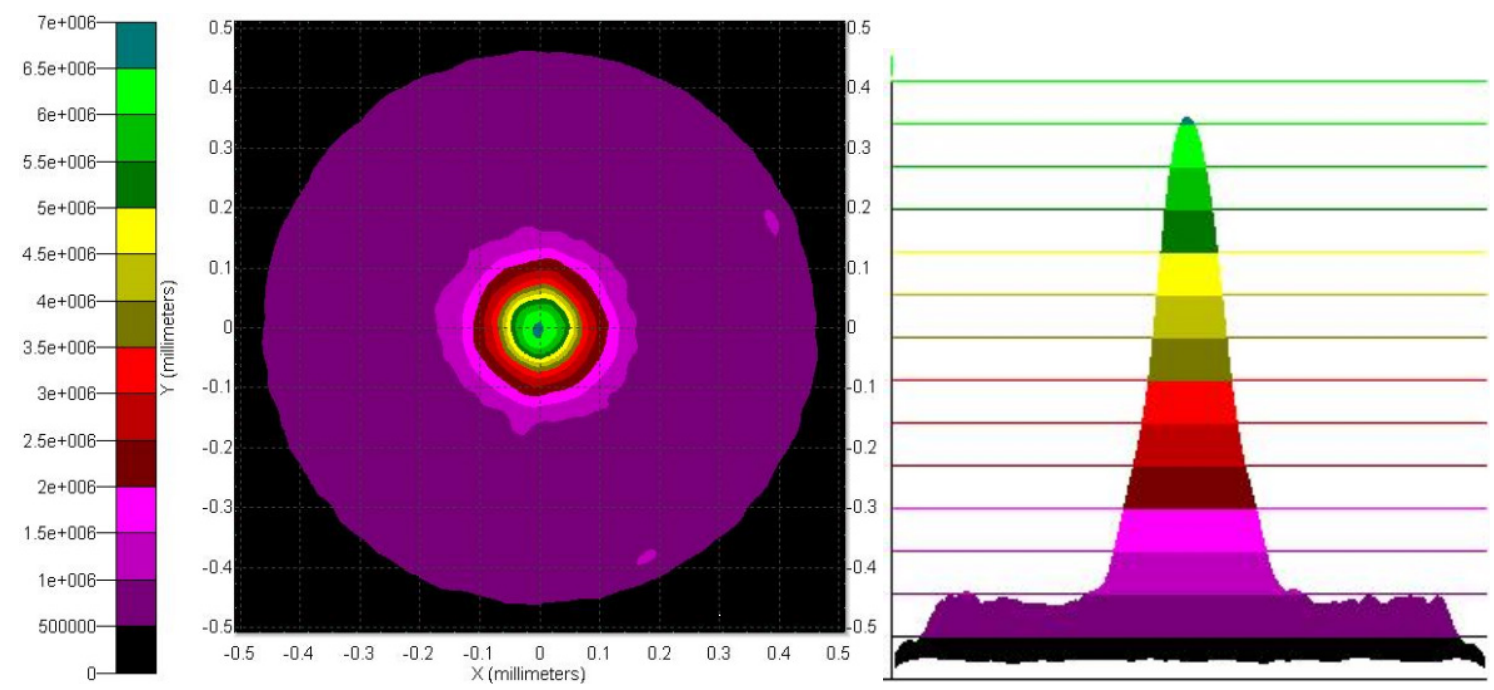

(a) 

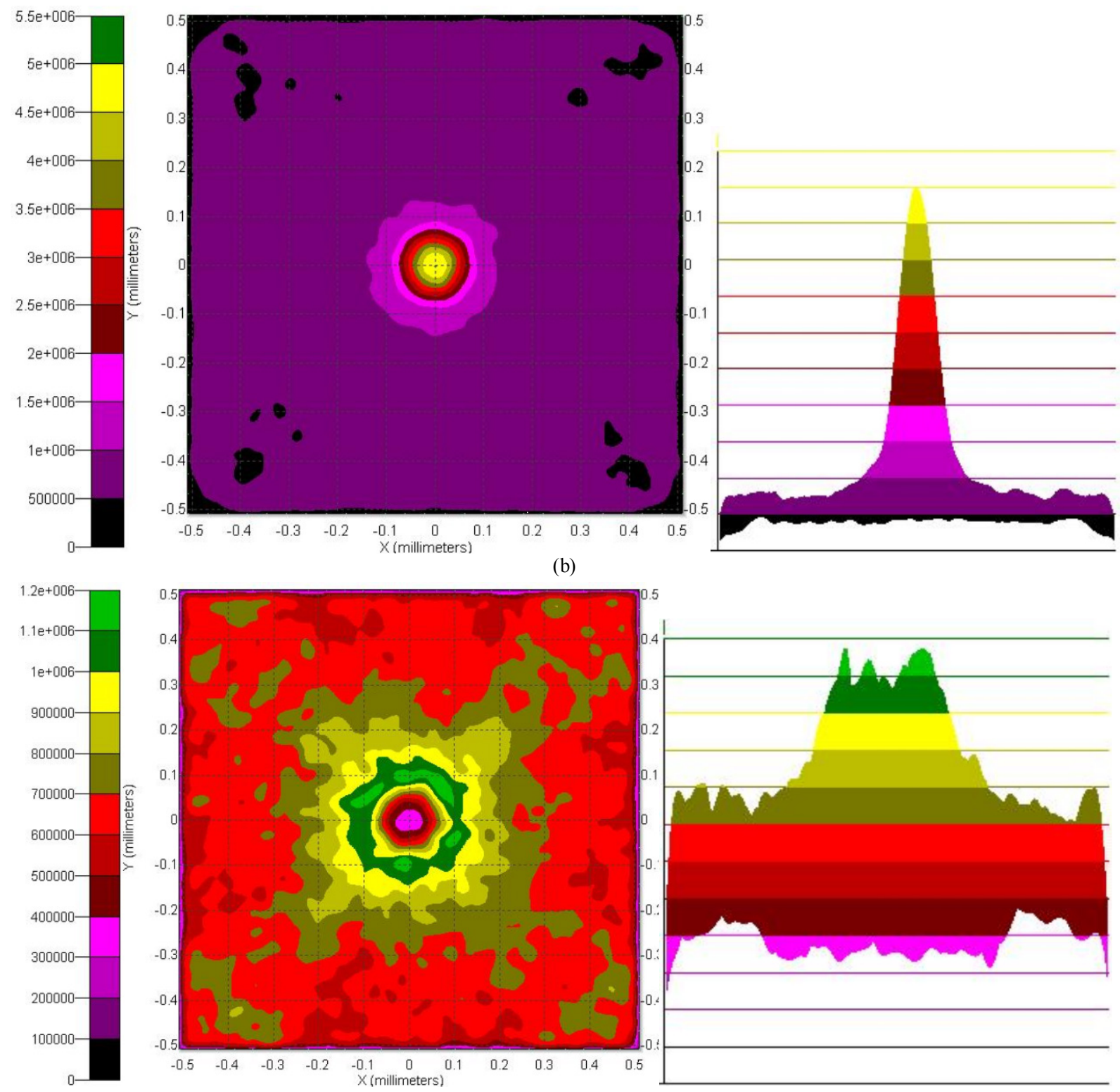

(c)

Figure 9. Flux distribution on the target (map and lateral profile) for different mixer lengths: (a) $2 \mathrm{~cm}$, (b) $2.5 \mathrm{~cm}$, (c) $3 \mathrm{~cm}$, with dielectric filling the kaleidoscope struct ures and part of the ex it of the CPC

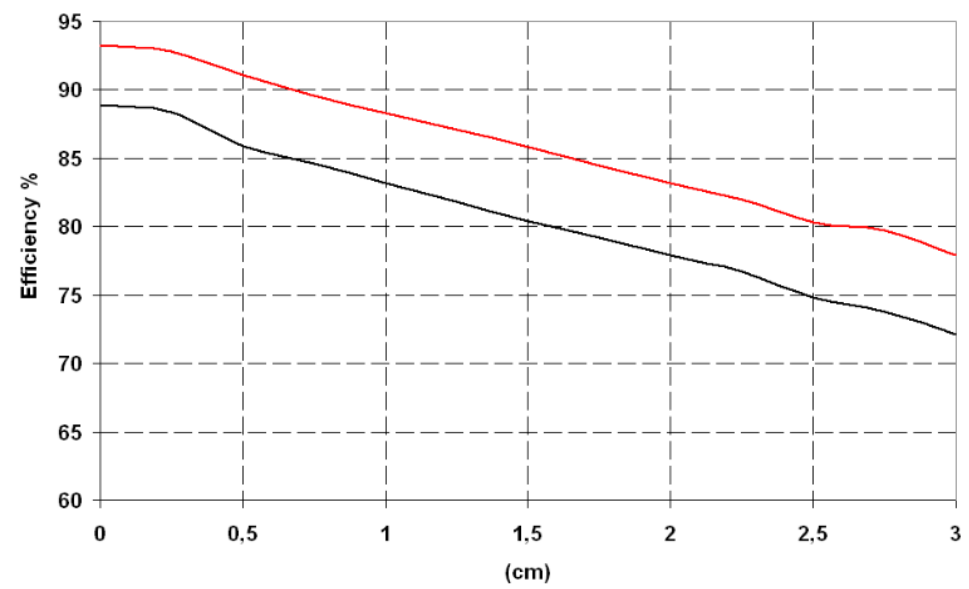

(a) 


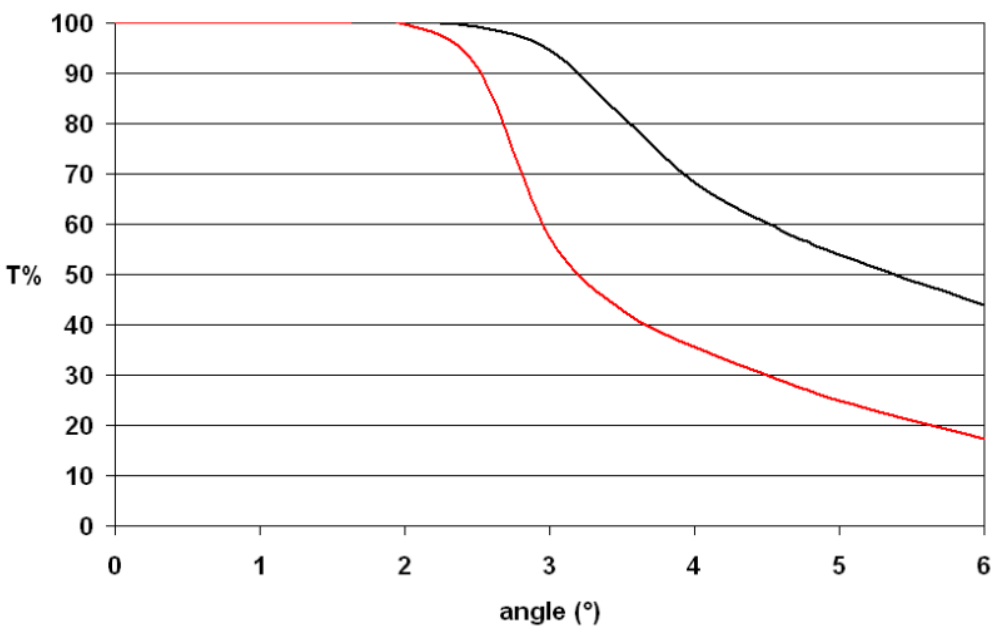

(b)

Figure 10. Optical efficiency vs. kaleidoscope length (a) and transmission angle curve (b) for the 3D-CPC with and without partially filling with dielectric (black and red line respectively)

The variation of the optical efficiency of the concentrator with the kaleidoscope length, for the reflector of the described properties, is reported in Fig. 10a for the cases of partial filled and of empty objects; diversely, the correspondent transmission-angle curves are in Fig. 10b.

To reduce the length of the mixer, a structured surface with V-shaped grooves can be employed, as described by Leutz[33]. Such a design increases the chaotic behaviour of the light rays path, working as an efficient mixing tricks to permit a length reduction.

Table 3. Optical efficiency for the $115 \times$ CPC with surface of $94.87 \%$ specular reflection, for a structure with a kaleidoscope of transparent material with $\mathrm{n}=1.49$ act ing for total internal reflection

\begin{tabular}{|c|c|c|c|}
\hline $\begin{array}{c}\text { Misalignment } \\
\text { angle }\left(^{\circ}\right)\end{array}$ & $\begin{array}{c}\text { Optical } \\
\text { efficiency } \\
\text { (without front } \\
\text { protective glass) }\end{array}$ & $\begin{array}{c}\text { Optical } \\
\text { efficiency } \\
\text { (With protect ive } \\
\text { glass without } \\
\text { ARC) }\end{array}$ & $\begin{array}{c}\text { Optical } \\
\text { efficiency } \\
\text { (With protective } \\
\text { glass with ARC } \\
\text { on both sides) }\end{array}$ \\
\hline $0^{\circ}$ & $89.6 \%$ & $82.8 \%$ & $87.0 \%$ \\
\hline $0.5^{\circ}$ & $89.7 \%$ & $82.9 \%$ & $87.0 \%$ \\
\hline $1^{\circ}$ & $89.8 \%$ & $82.9 \%$ & $87.0 \%$ \\
\hline $1.5^{\circ}$ & $89.3 \%$ & $82.5 \%$ & $86.6 \%$ \\
\hline $2^{\circ}$ & $87.5 \%$ & $80.9 \%$ & $85.0 \%$ \\
\hline $2.5^{\circ}$ & $79.8 \%$ & $73.8 \%$ & $77.4 \%$ \\
\hline $3^{\circ}$ & $49.6 \%$ & $45.9 \%$ & $48.2 \%$ \\
\hline
\end{tabular}

Another improvement of the optical efficiency can be achieved for structures with a lower concentration factor; indeed, in these cases, the average exit angle for the rays is lower and consequently also the number of reflection on the kaleidoscope walls. However, in order to achieve a high optical efficiency for real 3D objects the solution adopting a metal coated reflective kaleidoscope does not seem effective. An alternative solution adopts a kaleidoscope made of a transparent dielectric material working for total internal reflections (TIR). In such a way this part of the structure doesn't give a performance reduction strongly related to its length as in the previous cases with metalized, reflective surfaces. In Tab. 3 the optical efficiency of the T-CPC 30-cm long with a 4-cm long kaleidoscope made of a material with the optical properties of highly transparent glass, coated with a single layer of $\mathrm{MgF} 2$ as antireflection, is reported from simulations with the TracePro ${ }^{\circledR}$ software.

\section{Materials}

Because of the particular geometries required for the surface profiles, the fabrication of the structure can be done by plastic moulding. Computer controlled machining tools can work surface profiles with the CPCs curvature, with a precision level of $0.01 \mathrm{~mm}$; the smooth curvature required for these objects takes out the fabrication problems, own of Fresnel lenses, of achieving very sharp corners. The reflectance of the surface can be ensured by metallization with Al, Ag or applying reflective films; in any case the reflective coating must be properly covered with polymeric layers acting as protective barriers against moisture.

The large interest in high reflective, low cost materials for solar concentrator, both for $\mathrm{PV}$ as well as for thermal application has lead to a large body of literature on this is sue. Reflective materials have very good optical properties, even for large scale and low cost production[34-36]. For the here modelled structures, both reflective adhesive films as well as evaporated metal coatings directly deposited on the concentrator surfaces can be evaluated. For the particular geometries of the CPCs, the specular reflectance of the surfaces has to be evaluated at high angles of incidence for the light beam. Metallic reflectors have high insensitivity to the light impinging angle, as shown in the measured results in Fig. 11 for a glass coated with silver, tested for two different light wavelengths. The peak reflectance at higher angles in Fig. $11 \mathrm{~b}$ is due to the Fresnel reflection. Nevertheless, multi-layer polymeric films also demonstrate very high reflectance for all the incidence angles [38]. 


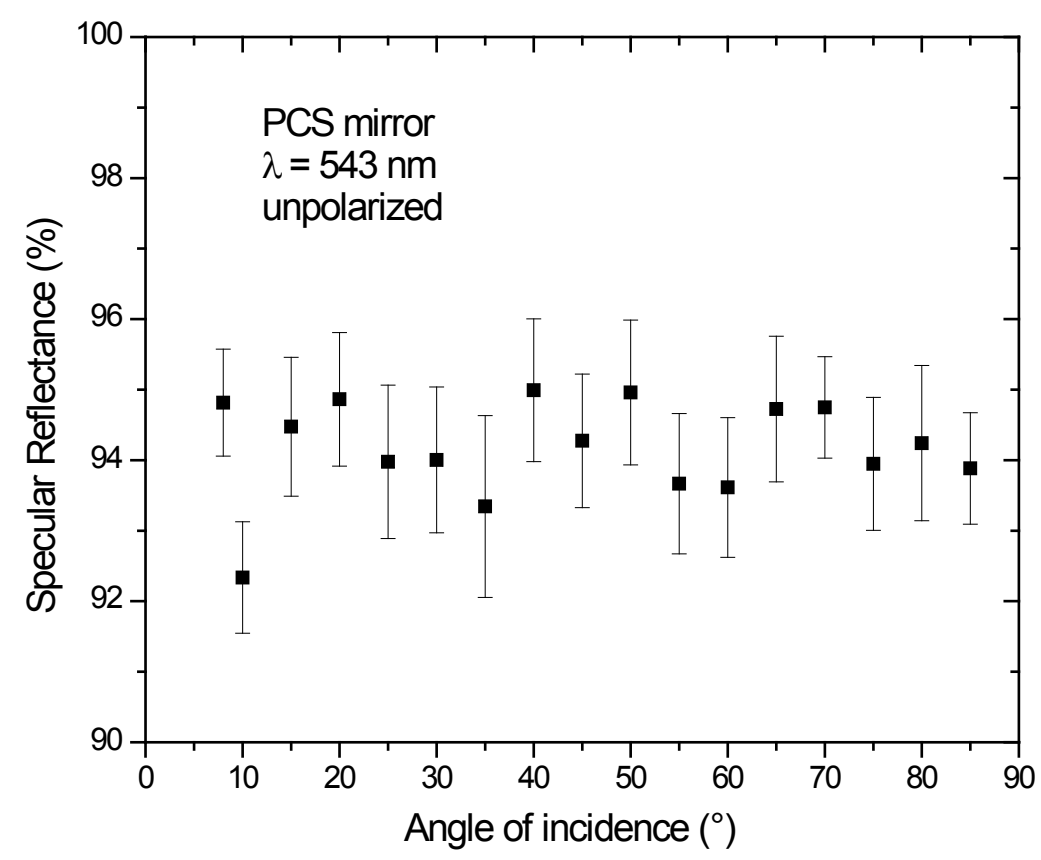

(a)

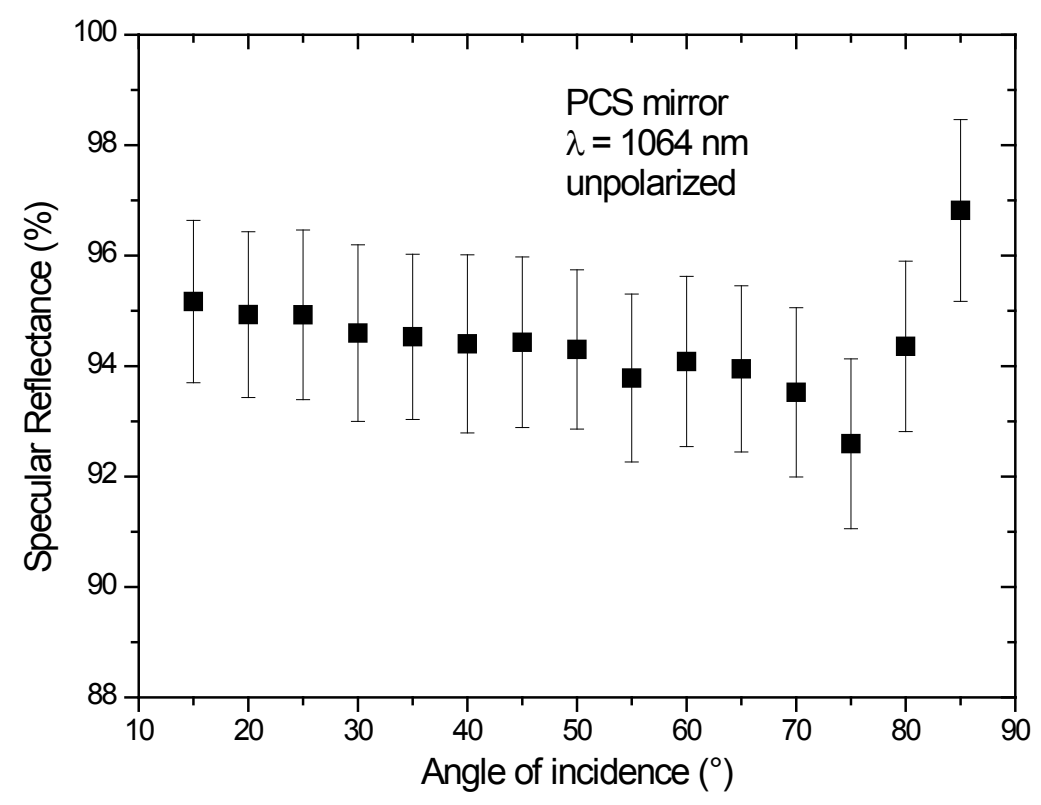

(b)

Figure 11. Experimental results of specular reflect ance for a silvered mirror at different angles of light incidence, for two different wavelengths, $543 \mathrm{~nm}$ (a) and $1063 \mathrm{~nm}$ (b). The measurements have been carried out at the glassed side of the mirror

The transparent, dielectric material here used for the simulations has refractive index $\mathrm{n}=1.49$. By varying the material it is possible to change the refractive properties in order to manage the angular acceptance.

\section{Conclusions}

The use of some CPC designs as primary concentrators for CPV has been described. Both 2D and 3D CPC structures have been evaluated and some particular solutions have been selected for possible photovoltaic applications. Historically, the large reflective area required for CPCs has limited their use to being secondary collectors or concentrators for low level of concentration, but, considering the very low price of currently available, high efficiency film reflectors, or the possibility of industrially coating small size structures with high reflective metals, this family of optical objects can be considered as a competitive choice for CPV applications.

The industrial development of very narrow linear concentrator cells has opened up the possibility of linear 
micro-concentrators. The particular shape of this kind of cells is suitable for linear concentrators, where each cell represents an element of a string of cells along a trough. The small width of the cells allows the use of CPCs, a class of concentrators not normally employed for large scale photovoltaic applications because of their intrinsically large dimensions, despite the fact that they have almost ideal non-imaging optical properties. By moving toward very small devices, it is possible to achieve concentrators of reasonable size with the inherent advantages of this class of optical object, i.e. their good tolerance at misalignment errors and the possibility of employing low cost but with very high reflective materials leading to high optical efficiency. Moreover, the very thin width of the cell permits efficient cooling at medium level concentration ranges, increasing the overall system efficiency.

3D-CPCs can be employed in the range of $100 \times$, permitting very high optical efficiency (closed to 90\%) for real devices produced with available industrial technology. The detrimental effect of the high non-uniformity in the light distribution at the target can be corrected with low optical losses, using a kaleidoscopic transparent dielectric material, acting for total internal reflections, working as light guide, and for mixing the radiation concentrated by the truncated CPC.

\section{REFERENCES}

[1] Mallick, T.K., Eames, P.C., Norton B., 2006, Non-concentrating and asymmetric compound parabolic concentrating building facade integrated photovoltaics: An experimental comparison, Solar Energy, 80(7), 834-49.

[2] NabinSarmah, Bryce S. Richards, Tapas K. Mallick, 2011, Evaluation and optimization of the optical performance of low-concentrating dielectric compound parabolic concentrator using ray-tracing methods, Applied Optics, 50(19), 3303-3310.

[3] Yuehong Su, Saffa B. Riffat, Gang Pei, 2012, Comparative study on annual solar energy collection of a novel lens-walled compound parabolic concentrator (lens-walled CPC), Sus-tainable Cities and Society, Vol. 4, 35-40.

[4] Antonimi, A., Butturi, M.A., Di Benedetto, P., Uderzo, D., Zurru, P., Milan, E., Stefancich, M., Armani, M., Parretta, A., Baggio, N., 2009, Rondine ${ }^{\circ}$ PV concentrators: Field results and developments, Progress in Photovoltaics: Res. Appl., 17(7), 451-459.

[5] Hatwaambo, S., Hakansson, H., Nilsson, J., Karlsson, B., 2008, Angular characterization of low concentrating PV-CPC using low cost reflectors, Solar Energy Materials and Solar Cells 92(11), 1347-1351.

[6] W.T. Welford and R. Winston, High Collection Nonimaging Optics, Academic Press, San Diego, 1989.

[7] Smestad, G., Ries, H., Winston, R., Yablonovitch, E., 1990, The thermody namic limits of light concentrators, Sol. Energy Mater., 21(2-3), 99-111.
[8] Parretta, A., Martinelli, G., Stefancich, M., Vincenzi, D., Winston, R., 2003, Modelling of CPC-based photovoltaic concentrator, Proc. of SPIE, Vol. 4829, pp. 1045-1047.

[9] Araki, K., Emery, K., Siefer, G., Bett, A.W., Sakakibara, T., Kemmoku, Y., Ekins-Daukes, N.J., Lee, H.S., Yamaguchi, M., 2005, Comparison of efficiency measurements for HCPV module with $3 \mathrm{~J}$ cells in 3 sites, Proc. 31 st IEEE PVSC, pp. 239-242.

[10] Jing, L., Liu, H., Lu, Z., Zhao, H., 2010, Design of compound Fresnel-R lenses for new high-efficient concentrator, Proc. of SPIE, Vol. 7785, pp. 77850K-77850K-10.

[11] Hinterberger, H., Winston, R., 1966, Efficient Light Coupler for Threshold Čerenkov Counters, Rev. Sci. Instrum., 37(8), 1094-1095.

[12] Baranov, V.K., Melnikov, G.K., 1966, Study of the illumi-nation characteristics of hollow focons, Sov. J. Opt. Technol., Vol. 33, pp. 408-411.

[13] M. Brunotte, A. Goetzberger, and U. Blieske, Two-stage concentrator permitting concentration factors up to $300 \mathrm{x}$ with one-axis tracking, Solar Energy, 56(3), 285-300.

[14] Brogren, M., Nostell, P., Karlsson, B., 2000, Optical Efficiency of a PV-Thermal Hybrid CPC Module, Proc. Eurosun 2000 - ISES Europe Solar Conference, Copenhagen, Denmark.

[15] Mohd. YusofHj. Othman, BaharudinYatima, Kamaruzzaman Sopianb, Mohd. Nazari Abu Bakara, 2005, Performance analysis of a double-pass photovoltaic/thermal (PV/T) solar collector with CPC and fins, Renewable Energy, 30(13), 2005-2017.

[16] David A.G. Redpath, Harjit Singh, Christopher Tierney, Philip Dalzell, 2012, An Experimental Comparison of two Solar Photovoltaic - Thermal (PVT) Energy Conversion Systems for Production of Heat and Power, Energy and Power, 2(4), 46-50

[17] Franklin, E., Coventry, J.S., 2002, Effects of Highly Non-uniform Illumination Distribution on Electrical Perfor-mance of Solar Cells, Proc. ANZSES Solar Conference, Newcastle, Australia.

[18] Antonini, A., Stefancich, M., Vincenzi, D., Malagù, C., Bizzi, F., Ronzoni, A., Martinelli, G., 2003, Contact grid optimization methodology for front contact concentration solar cells, Solar Energy Materials and Solar Cells. 80(2), 155-166.

[19] Leutz, R., Suzuki, A., Akisawa, A., Kashiwagi, T., 2001, Flux uniformity and spectral reproduction in solar concentrators using secondary optics, Proc. ISES Solar World Congress, Adelaide, Australia.

[20] Leutz, R., Suzuki, A., Akisawa, A., Kashiwagi, T., 2001, Nonideal concentration of nonimaging linear Fresnel lenses, Proc. Nonimaging Optics: Maximum Efficiency Light Transfer VI, San Diego, CA. The International Society for Optical Engineering, 2001, pp.100-109.

[21] Ries, H., Gordon, J.M., Lasken, M., 1997, High-flux photo-voltaic solar concentrators with kaleidoscope-based optical designs, Solar Energy 60(1), 11-16.

[22] Chen, M.M., Berkowitz-Mattuck, J.B., Glaser, P.E., 1963, The Use of a Kaleidoscope to Obtain Uniform Flux Over a 
Large Area in a Solar or Arc Imaging Furnace, Applied Optics 2(3), 265-272.

[23] Kreske, K., 2002, Optical design of a solar flux homogenizer for concentrator photovoltaics, Applied Optics, 41(10), 2053-2058.

[24] Luque, A., Sala, G., Arboiro, J.C., Bruton, T., Cunningham, D., Mason, N., 1997, Some Results of the EUCLIDES Photovoltaic Concentrator Prototype, Prog. Photovoltaics: Res. Appl., Vol. 5, pp. 195-212.

[25] Coventry, J.S., 2005, Performance of a concentrating photo-voltaic/thermal solar collector, Solar Energy, 78(2), 211-222.

[26] Leutz, R., Suzuki, A., Akisawa, A., Kashiwagi, T., 2000, Shaped nonimaging Fresnel lenses, J. Opt. A: Pure Appl. Opt. 2(2), 112-116.

[27] Leutz, R., Suzuki, A., Akisawa, A., Kashiwagi, T., 1999, Design of a nonimaging Fresnel lens for solar concentrators, Solar Energy, 65(6), 379-387.

[28] Franklin, E., Blakers, A., 2004, SLIVER ${ }^{\circledR}$ Cells for Con-centrator Sy stems, Proc. 19th EPSEC, Paris, France.

[29] Blakers, A.W., Deenapanray, P.N.K., Everett, V., Franklin, E., Jellett, W., Weber, K.J., 2005, Recent Developments in
SLIVER Cell Technology, Proc. 20th EPSEC, Barcelona, Spain.

[30] V. Díaz, J. Alonso, J.L. Alvarez, C. Mateos, The Path for Industrial Scale Production of Very High Concentration PV Systems, Proc. 20th EPSEC, June 6-10, 2005, Barcelona, Spain.

[31] Anton, I., Sala, G., 2005, Losses caused by dispersion of optical parameters and misalignments in PV concentrators, Prog. In Photovoltaics: Res. Appl. 13(4), 341-352.

[32] R. Winston, R, C. Gee, Nonimaging light concentrator with uniform irradiance, US Patent 6,541,694 B2, April 1, 2003.

[33] Leutz, R., Ries, H., 2003, Squaring the Circle - The Use of Microstructures for Converting and Homogenizing Beam Patterns, Proc. SPIE Vol. 5186, Design of Efficient Illumination Systems, 106, Nov. 10, 2003; doi:10.1117/12.506792.

[34] Nostell, P., Roos, A., Karlsson, B., 1998, Ageing of solar booster reflector materials, Sol. Energy Mater. Sol. Cells, 54(1-4), 235.

[35] B.M. Clive, "Very low cost PV concentrators", ETSU S/P2/00349REP, DTI/Pub URN 01/1120.

[36] J. Harrison, "Investigation of Reflectivity Materials for the Solar Cooker", Florida Solar En er gy Center, 24-12-2001. 